and that cavities were seen mainly in the posterior parts of the upper and middle lung fields.

Examination of the blood revealed a number of interesting points. The sedimentation rate can be temporarily raised in the non-cavitated forms of noninfective massive fibrosis, but in aseptic or ischaemic necrosis it remains constantly above $20 \mathrm{~mm}$. An isolated high E.S.R. is of no value in the diagnosis of tuberculosis, and amongst the tuberculous coalworkers a constantly high E.S.R. is seen only in those with cavitation. The level of blood fibrogen, which increases with the stage of pneumoconiosis and with cavitation of tuberculous lesions, is occasionally independent of the E.S.R., especially after treatment has been begun. Blood proteins, studied by paper electrophoresis, show a decrease of the albumin and an increase in the globulins, related to the stage of fibrosis. When cavitation is present, the $\alpha_{2}$-globulins increase more than the other fractions. The mean level of glycoprotein increases with the stage of pneumoconiosis, with progression of massive fibrosis and in tuberculosis, in which also there is a high glycoprotein-polysaccharide ratio. C-reactive protein was often found in early and advanced massive fibrosis, in aseptic necrosis, and in active tuberculosis. It was concluded that the diagnostic significance of the proteins was limited by great individual variations and by the somewhat similar effect of pneumoconiosis and tuberculosis on them.

The haemagglutination reaction of MiddlebrookDubos was found to be useful in the differentiation of tuberculous cavitation from the aseptic (or ischaemic) necrosis of massive fibrosis. Prignot regards this fact as being opposed to the thesis that tuberculosis is always responsible for progression in massive fibrosis.

His studies also included the examination of the sputum for tubercle bacilli and dust; the Mantoux reaction; macroscopic and microscopic pathology of the lungs; bronchoscopy; radiography, including tomography and the results of treatment. He recommends that any preventive scheme should include pre-employment radiograph examination and systematic tuberculin tests. Men with negative Mantoux reactions should be vaccinated with B.C.G. until they are positive, and this should be followed by prophylactic chemotherapy.

This important book is (as Professor Lambin says in his graceful introduction) impeccably printed and illustrated, and there are some beautiful coloured reproductions of large sections of coalworkers' lungs prepared in Professor Gough's laboratory at Cardiff. It includes an extensive bibliography, but no index.

\section{A. I. G. McLaughlin.}

Elongation Treatment of Low Back Pain. By George S. Hassard, and Charles L. Redd. (Pp. xvi + 78; 47 figures; 36s.) Oxford: Blackwell Scientific Publications; Springfield: Thomas. 1959.

This book, intended primarily for physiotherapists and remedial gymnasts, describes a new practical effort towards prevention and treatment of low back pain in industry.
Treatment is based on the idea that a collagen fibrous tissue contracts following injury, and under other conditions. It is claimed that this tissue can be elongated by specialized physical medicine, with relief of symptoms and a $90 \%$ reduction of sick leave due to the low back pain.

The authors try to explain, by one pathology, the many conditions affecting the back, but the supporting reasons are unimpressive and not very sound.

The importance of backache in industry is appreciated and good advice is given on correct posture.

In this country we should be opposed to this treatment being carried out by anyone except physiotherapists, but the book suggests that it can be done by nurses, remedial gymnasts and even the works foreman.

Figure 1 shows a typical case of acute disc prolapse but is called sprain of the ligaments and strain of muscle fascia and connective tissue. Figure 5 is incorrectly labelled with regard to the peroneal and sciatic nerves.

At the end of the book which is well produced and attractive all the usual methods of physical medicine are mentioned.

$$
\text { G. P. Arden }
$$

Filters for Use during Welding and Similar Industrial Operations. British Standard 679:1959 and Equipment for Eye, Face and Neck Protection Against Radiation Arising during Welding and Similar Operations. British Standard 1542 : 1960. London: British Standards Institution.

British Standard 679 relates to filters for eye protection and includes requirements for quality, for classification for both density and colour (this latter applying only to circular filters for gas welding), for thickness, and for optical uniformity. Methods are given of testing materials for permanence, for resistance to heat and moisture, and for flammability, together with recommendations for the grades of filters to be used for different types of welding. The permissible kinds of materials have been increased to include plastics.

British Standard 1542 specifies requirements for equipment to protect an operator above the shoulders against radiation of wavelength greater than $2000 \AA$ when engaged in welding, cutting, and similar operations. Methods of testing materials are given for resistance to corrosion of metal components, flammability, impact strength of spectacle frames, electrical insulation, and disinfection of equipment. A strong recommendation is put forward that a $4 \frac{1}{4}$ in. $\times 3 \frac{1}{4}$ in. $(108 \mathrm{~mm} . \times 82 \mathrm{~mm}$. $)$ filter should be specified for all new equipment (helmets and shields) intended for use in the United Kingdom.

It is surprising that in this publication emphasis should be laid on infra-red radiation rather than ultra-violet from gas-shielded arc welding and cutting, and vice versa from gas welding and cutting.

These two British Standards are complementary to B.S. 2653 " Protective clothing for welders", and if the welder is supplied with equipment conforming to their specifications then he will have considerable protection against some of the inherent hazards of the processes he employs.

P. J. R. Challen 